$5-7$

\title{
Conflict of evidence or conflict of interest?
}

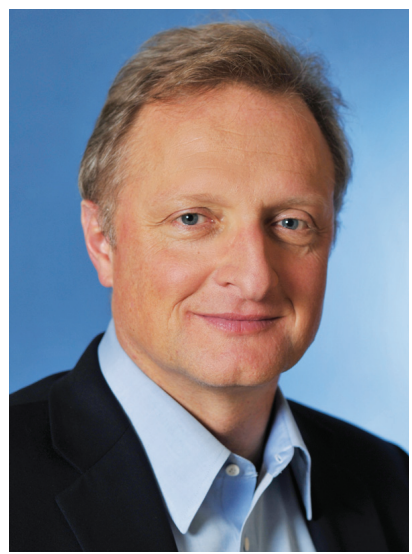

Jens Chapman
We at EBSJ appreciate a substantial and mostly positive echo to the editorial titled "BMP: evidence in the name of science?" (EBSJ Volume 2, Issue 4). Thank you to all who have voiced their interest and support of our unique publication. Other publications have also echoed the desirability of a reevaluation of the methodology and conclusions of the article by Carragee et al titled: "A critical review of recombinant human bone morphogenic protein-2 trials in spinal surgery: emerging safety concerns and lessons learned." [1] A particularly detailed vocal response has appeared in a trade publication named 'Orthopaedics This Month' by Robin Young, CFA, and is titled “Under Carragee The Spine Journal lives dangerously." [2] This non-peer reviewed article extensively reviewed the data in The Spine Journal article as presented and then used public federal data sources on complications of spine fusions with and without BMP-2, and found a substantially lower incidence of reoperations in the BMP group. The author (who is the same person as the editor-in-chief and publisher) called for a formal reinvestigation of the BMP data and outright retraction of the assertions made in The Spine Journal article, which had stated that complications were suppressed or not presented by the investigators of the BMP-2 FDA trials. The purpose of this editorial message is, however, not to rehash the continued debate revolving around BMP-2 possibly being linked with increased rates of retrograde ejaculation (or not) and other complications (such as a suggested increased cancer rate with BMP-2) but to raise some thoughts on the underlying accusations of unresolved conflict of interest (COI) of its original investigators.

As a profession our spine community continues to struggle with public perceptions and management of COI. Conflict of interest is justifiably undesirable due to its penchant of creating bias and injustice as its final manifestation (Table 1). The practicality of managing COI in the present day appears to be in a rather unsatisfactory state of affairs.

Table 1 Common examples of COI (extracted with modifications from Wikipedia).

\begin{tabular}{ll}
\hline $\mathbf{5}$ types of COI occurrence & General theme of action \\
\hline "Self dealing" & Person in power is on both sides of deal. \\
\hline Outlying work & Both activities contradict one another \\
\hline Nepotism & Family and friends receive jobs etc. \\
\hline Cifts and in-kind services & Presents for individuals and companies who do business with \\
\hline "Pump and dump" & Inflation of business or stock price through 'insider' knowledge \\
\hline
\end{tabular}

Anyone in attendance at the most recent North American Spine Society 2011 meeting held in Chicago, IL, will probably agree with the observation that speakers were held to provide unprecedented explicit disclosures in both qualitative and quantitative domains just stopping short of disclosing bank statements and annual tax returns. Did this improve the public's awareness of the presenter's potential COI? The reality of most presentations was that the sheer number of disclosures hurriedly rushed through by most speakers in slides and abstracts made any actual understanding and discussion of potential COI unrealistic and thus precluded any effective management. Interestingly, I found several presentations by industry employees within the academic program of this meeting. While some listed a number of disclosures, several made no reference of their employee status within the company whose technology was being presented (invariably in a favorable light) and thus was apt to elude audience scrutiny. 
While the focus of COI has centered almost exclusively on largely profit-oriented themes of industry and medical profession relations, far less (if any) attention has been placed on other forms of COI. Consider, for instance, the case of an investigator of a large clinical trial whose sizeable grant is tied to enrollment of a certain number of study subjects, and who has seriously fallen behind in recruitment. It is not difficult to imagine that this investigator may fall subject to enrollment pressure by surreptitiously changing patient recruitment practices, especially if there are external penalties or professional embarrassment looming. This is a probably far greater reality in large federally/nationally funded grants than is commonly assumed and may obviously impact results. Undisclosed and perhaps undisclosable socio-political preferences may also alter formulation of study hypothesis and may preselect grant applications, especially those provided by federal/ national funding entities.

Medical publications, with their opinion-building influence affecting wide areas of healthcare, are another commonly underappreciated example of COI. How are we vetting the potential COI of editors of medical publications and the criteria with which they decide to publish or not publish articles? For instance, what prompts the editor of an influential journal, such as The Spine Journal, to publish an article of such likely controversial and thus attention-getting nature as the BMP-2 critical review in his own journal? Is it less scrutiny or could he be interested in drawing attention to his publication? For an industry trade publication such as Orthopedics This Week the unbroken chain of company owner - editor - author presents a 'continuum of interest' within the same person, actually seems to be a more forthright arrangement than the example of a major scientific journal with its multiple listings in academic online services, where the undeclared coincidence of the author of a high-profile paper being identical with the Editor-in-Chief could leave doubt as to its potentially circumspect motives.

This has not been an isolated example in the recent past. The subject of vertebroplasty in spine fractures is another case of a high-profile technology controversy in spine. There have been two highly publicized major prospectively randomized controlled trials (PRCTs) that found no substantial differences between their interventional groups and the (sham) control groups [3,4]. Both of these studies were published in the New England Journal of Medicine (Editor-in-Chief: Jeffrey M Drazen, MD). There were two other major PRCT's that looked at vertebroplasty and kyphoplasty compared to nonoperative care, which found considerably better results in the intervention groups compared to the nonoperative control groups. Both of these studies were published in Lancet (Editor-inchief: Richard Horton, BSc MB FRCP FMedSci) [5, 6]. We don't know the circumstances that led one highly reputed journal to have published high-profile studies with big public resonance that cast doubt on vertebroplasty in the treatment of osteopenic vetrebral compression fractures, while another very high profile medical journal comes up with the exact opposite in its publications, but it would be interesting to learn more about the circumstances which lead to this distribution of articles.

Table 2 Actions that can be taken (extracted with modifications from Wikipedia).

\begin{tabular}{ll}
\hline $\mathbf{5}$ types of COI mitigation & General theme of action \\
\hline Removal & Ideally avoid any COI in the first place \\
\hline Disclosure & Threshold levels established by societies, government bodies \\
\hline Recusal & Abstain from any activities with COI \\
\hline Third party independent review & Independent up-front investigation through outside organization \\
\hline Codes of ethics & Set standards of conduct \\
\hline
\end{tabular}




\section{REFERENCES}

1. Carragee EJ, Mitsunaga KA, Hurwitz EL, et al (2011) Retrograde ejaculation after anterior lumbar interbody fusion using rhBMP-2: a cohort controlled study. Spine J; 11(6):511-516.

2. Young R (2011) Under Carragee the Spine Journal lives dangerously. Orthop This Week; 3:24-36.

3. Buchbinder R, Osborne RH, Ebeling PR, et al (2009) A randomized trial of vertebroplasty for painful osteoporotic vertebral fractures. $N$ Engl J Med; 361(6):557-568.

4. Kallmes DF, Comstock BA, Heagerty PJ, et al (2009) A randomized trial of vertebroplasty for osteoporotic spinal fractures. $N$ Engl J Med; 361(6):569-579.

5. Klazen CAH, Lohle PNM, de Vries J, et al (2010) Vertebroplasty versus conservative treatment in acute osteoporotic vertebral compression fractures (Vertos II): an open-label randomised trial. Lancet; 376: 1085-1092.

6. Wardlaw D, Cummings SR, Van Meirhaeghe J, et al (2009) Efficacy and safety of balloon kyphoplasty compared with non-surgical care for vertebral compression fracture (FREE): a randomised controlled trial. Lancet; 373(9668):1016-1024.

7. McGreevey S (2009) Policies regarding IRB members' industry relationships often lacking. Available at: www.eurekalert. org/pub_releases/2009-03/mghpri032309.php

8. Carragee EJ, Hurwitz EL, Weiner BK, et al (2011) Future directions for The Spine Journal: managing and reporting conflict of interest issues. Spine J; 11(8):695-697.
From these examples one may deduct that to date the issues of COI are not satisfactorily resolved by a mere disclosure of potentially relevant financial relations afflicting each individual and that we have a long way to go in our efforts to recognize and then mitigate the multidimensional and pervasive nature of COI [7] (Table 2). Ultimately, all of us are intrinsically conflicted individuals beyond public declarations and disclosures of our financial and organizational bearings. Our internal values- as shaped by our history, life experiences, knowledge, predispositions and outright prejudices-are the ultimate and probably most prevalent and powerful of all conflicting interests. Appreciating this fact and opening our minds to the multi-tiered undercurrent of other forms of COI would be a start until we formulate ways of better identifying and then managing the important subject of COI. And then there are some simple things we can do now: let the facts (as in 'the evidence') speak for themselves as much as possible and frown upon editors-in-chief publishing their own scientific articles in their journals [8].

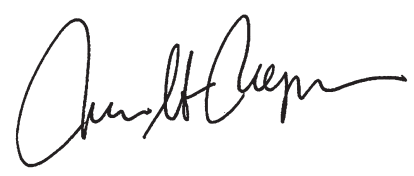

Jens Chapman

Editor-in-chief 